\title{
A redescoberta do único
}

\author{
HERBERT GEORGE WELLS
}

$\mathrm{O}$ TítUlo ORIGINAL DESTE artigo era A falácia do substantivo. Este foi alterado pelo presente, que o autor considera ser igualmente expressivo e, de longe, preferível, dada sua silenciosa grandiosidade. Qualquer um deles levará nossa pretensão à maioria dos leitores, mas possivelmente haverá uns poucos, aqui e ali, para quem ambos não terão qualquer significado. A eles poderíamos, talvez, a título de informação introdutória, ou prospecto, fornecer umas poucas notas acerca do escopo, valor e necessidade de nosso assunto.

A redescoberta do único é a redescoberta de um fato bastante óbvio mas, ainda assim, negligenciado. É de grande - praticamente universal - interesse, e de aplicação igualmente universal. Para pessoas inteiramente práticas, ela tem valor ao expor a injustiça criminosa, seja de normas gerais sobre tílburis, seja de uma inspeção de pesos e medidas. Para aqueles que amam a sutil subjetividade e não cruezas objetivas, e que acham impossível a repetição de fatos, ela constitui uma inestimável e preciosa justificação; já para os cientistas, é importante por destruir a teoria atômica. Ela choca o filósofo que se abriga na razão pura pois chacoalha a lógica da mesma forma que terremotos agitam as torres elevadas. Ela deve - vai - dizimar todos os pontos de vista do homem judicioso como uma peste arrasa uma cidade. Entre outras coisas, depois de um século de crítica destrutiva, ela reinstala os milagres e profecias em seus antigos patamares. Mostra que todos aqueles escritores científicos que tão fluentemente vêm falando do reino da lei inflexível têm estado seriamente enganados. Restaura as providências especiais e as asserções não-verificadas ao estoque das coisas acreditáveis e, para a imaginação humana, a liberdade. Para os clérigos, forçados a controvérsias em paróquias urbanas, para os acadêmicos clássicos - que, como mestres, acham a Educação de Spencer uma maldição e uma ameaça - e para o sexo frágil e ilógico de todo lugar, essa redescoberta vem como uma dádiva ou bênção especial. Devidamente financiada, ela pode se estabelecer como um culto. O Budismo Teosófico e o Catolicismo Místico, refúgios do ceticismo vulgar e militante usados pelos superficialmente refinados, ganharão um terceiro rival. Um novo lema pode ser, e de fato está sendo, lançado no mercado: Sejamos únicos - em bandos; pois a ambição de nossos rapazes e donzelas de, a qualquer preço, serem agitados $e$ excêntricos, é o aspecto moral inconsciente dessa grande redescoberta.

A coisa toda pode, assim como a teoria da gravitação, ser expressa numa só sentença embora, como aquela teoria, seja o resultado de muitos séculos de raciocínio. 
Numa sentença, Todo ser é único, ou, nada é estritamente igual a qualquer outra coisa. Implica, portanto, que atingimos a idéia de seres similares apenas através da desconsideração inconsciente ou deliberada de uma infinidade de pequenas diferenças. Nenhum par de animais, por exemplo, é similar, como qualquer pastor ou criador de pássaros ou cães poderá dizer. Se examinados cuidadosamente, quaisquer dois tijolos, ou moedas, ou bolas de gude, mostrarão diferir em tamanho, forma, superfície, matiz - em detalhes infinitos, conforme você faça sua investigação mais profunda e detalhada. "Tão semelhantes quanto duas ervilhas em uma vagem" é um provérbio que, como a maioria dos provérbios, fixa um conceito errôneo, como qualquer um pode ver por si mesmo quando é época de ervilhas. E assim, na menor porção de terra ou nas mais triviais coisas da vida existe, se cuidarmos em ver, o único e o sem precedentes. Como nos ensina São Pedro $\mathrm{e}$, mais modestamente, Wordsworth -, não há nada à nossa volta que seja comum ou negligenciável. Assim, com um breve parágrafo ou um rápido raciocínio, os padrões se desprendem dos olhos do leitor e ele faz a redescoberta do único.

Suas conseqüências lógicas são tão grandes que pediríamos sua paciência por um momento a fim de assentarmos nossa posição antes de passarmos a elas. Podemos imaginar algumas objeções ao que dissemos. $\mathrm{O}$ caso de duas balas que seguem uma à outra a partir de um molde poderia, talvez, ser levantado pelo indivíduo pouco científico. Mas, na verdade, o mesmo molde jamais produz duas balas iguais: elas terão peso a mais ou a menos; o molde estará sempre um pouco mais gasto desde que a última bala fora moldada; o próprio chumbo sofre variações de temperatura e suas impurezas variam. Novamente, os delicados cristais de um precipitado parecem iguais até que os testemos com um micrômetro, microscópio, polarizador ou através de testes microquímicos. Encontraremos, então, uma individualidade razoável em termos de tamanho, imperfeições, tensão etc. As estrelas do céu e a areia das praias não são, evidentemente, seres únicos devido apenas a sua distância e tamanho, respectivamente. Em todo lugar, a repetição desaparece e o único é revelado conforme a sensibilidade e a análise se tornem mais sutis. E, uma vez que os adjetivos são derivados dos substantivos, segue-se que a unicidade vai além das coisas e atinge as propriedades. $\mathrm{O}$ vermelho de uma pétala de rosa se parece com o vermelho de outra porque o homem que a vê é cegado pela insuficiência óptica e pelo hábito mental. Coloque-as lado a lado: o matiz é o mesmo? Se você pensa assim, aconselhe-se com um artista realmente capaz de pintar flores. Atualmente, toda a educação tende a se tornar prática, embora ainda possamos encontrar escolas de metafísicos nos campos, seriamente engajados em desfolhar margaridas.

Assim, o substantivo é uma ligação verbal de um grupo mais ou menos arbitrário de únicos. Quando os tomamos distributivamente, os limites ficam repentinamente vagos. Uma constante nos ensinamentos do mais eminente geólogo vivo [aqui, Wells se refere a John Wesley Judd] é que tudo se transforma em tudo o mais através de gradações insensíveis. 
Ele apresenta a seus alunos uma imagem do universo que não difere muito de um esboço em aquarela que, tendo caído em uma bacia, ficou manchado. O substantivo cadeira, por exemplo, é bem definido para o leitor até que ele comece a pensar; aprecie, então, os limites da dúvida! Cadeiras de balanço, divãs, sofás; o que é isso que não foi descrito - cadeira ou poltrona? E esta: cadeira ou banqueta? Aqui, de novo, temos uma cadeira de jardim, um banco ou um chevalde-frise? (1) E, onde se traça a linha entre cadeira e lenha para fogueira? Mas a pessoa comum, quando fala de diversas cadeiras, nunca sente a iminência dessa dificuldade. Ela imagina um único aparato para sentar que lhe é familiar e, dando para ele uma espécie de olhadela mental múltipla viciosa, vê o que é completamente impossível no mundo real: tantas outras cadeiras idênticas a esse aparato.

Mas, a partir da teoria de nossa redescoberta, número é uma reduplicação puramente subjetiva e ilusória de únicos.

É extremamente interessante traçar a gênese desse engano humano acerca do número. Ele cresceu com o desenvolvimento da mente e é, estamos bem preparados para admitir, uma característica necessária do pensamento. Podemos notar aqui, entre parênteses, que não fazemos qualquer proposta para superar o raciocínio comum através de um novo método. Estamos, em harmonia com a biologia moderna, apenas afirmando um fato simples sobre ele. A razão humana, à luz do que foi dito antes, aparece como um processo orgânico conveniente baseado num erro fundamentalmente feliz e pode - embora a premissa seja contra essa visão - nos levar para longe, e não para mais perto, da verdade absoluta das coisas. A raison d'être da mente humana é evitar o perigo e conseguir alimento - pelo menos é isso que os naturalistas nos dizem. Seus poderes de raciocínio são instrumento tão bom na busca da verdade quanto o é o focinho de um porco e ela pode tentar chegar ao
Wells e a ficção científica

JeSUS DE PAULA ASSIS*

$M$

IL NOVECENTOS e noventa e cinco marca os 100 anos da publicação da mais influente novela de ficção científica jamais escrita: A máquina do tempo, de Herbert George Wells (1866-1946). Foi sua primeira experiência em ficção, embora já fosse autor de artigos jornalísticos - especialmente de divulgação científica - que enchiam páginas das então nascentes Pall Mall Magazine ou Fortnightly Review. Foi nesta última que Wells estreou, em 1891, com um provocativo artigo: A redescoberta do único.

No texto, Wells desenvolve a idéia de que substantivos - e, portanto, os adjetivos e números, que neles têm sua origem - não são mais que ficções, meios que o homem utiliza para memorizar uma natureza de variedade infinita, encaixando-a em umas tantas palavraschave. Assim, não existe cadei$r a$, mas uma infinidade de objetos diferentes que, se não fossem empacotados em um substantivo, certamente esgotariam a memória e impossibilitariam a comunicação.

Conseqüência direta disso é que todo conhecimento - e, principalmente, a fração mais segura desse conhecimento, a ciência natural - é posto em dúvida. O que existe, na verdade, é uma infinidade de seres e tudo o que a ciência pode fazer é abstrair sua riqueza para 
fundo das coisas tanto quanto uma toupeira ao cavar. Isso, no entanto, está fora do escopo deste artigo e é, de qualquer forma, prematuro.

Os primeiros substantivos do homem primitivo não foram, quase certamente, substantivos comuns. Eram termos singulares que expressavam certas relações entre ele, como centro do universo, e esse mesmo universo. Havia pai, que o alimentava; casa, onde se abrigava; e, homem, o adversário que ele odiava e contra quem tramava. Da mesma forma, na fase de recapitulação do desenvovimento da criança, ela usa $p a, m a$, bicho, estritamente como nomes próprios. Esses termos simples tornam-se substantivos comuns à medida que a experiência aumenta e as analogias aparecem. Bem cedo, o homem exauriu seu estoque primitivo de grunhidos, balbuceios e bufos: sua memória fonética, e geral, era fraca e sua capacidade de diferenciação, portanto, superficial. Em conseqüência, foi obrigado a passar por cima da unicidade e reunir coisas aparentemente similares sob o que era, para fins práticos, o mesmo som. Seguiu-se então o fácil passo de embaralhar esses substantivos em formas duais ou plurais. E então, a partir de uma mixórdia de demonstrativos e de substantivos decompostos, desenvolveram-se os números - desenvolveram-se e deram frutos, tal como um bosque mental de upas.

Eles estupidificam as pessoas. Quando ensinamos uma criança a contar, envenenamos sua mente de maneira irrevogável. Quando um homem fala de mil tijolos, nunca sonha que, na verdade, está falando de uma coleção única de únicos que sua mente é incapaz de dominar individualmente. Quando fala em mil anos, nunca cruza sua mente a suspeita de que está se referindo a uma série única de revoluções únicas daquela parte da Terra que habitamos; ainda assim, se ele for um homem educado, saberá perfeitamente bem que a forma da órbita terrestre e a velocidade da Terra são coisas em constante mudança! Ele está inoculado com o vírus aritmético. Deixa que um relógio e um calendário o ceguem para o fato de que todo momento em sua vida é um milagre e um mistério.

Tudo o que se diz aqui acerca de substantivos e de números tem uma aplicação óbvia em termos lógicos. Não é preciso falar mais nada às pessoas estritamente lógicas para finalmente convencê-las do absurdo de ser estritamente lógico. Elas brincam com as palavras com que trabalham como se fossem ferramentas confiáveis, instrumentos de aço, quando, na verdade, elas mais se parecem com serras ou machados de gelo quando o termômetro flutua em torno de zero grau centígrado.

O corolário mais indisputável da redescoberta é a destruição da teoria atômica. Não há absolutamente base na experiência humana para a suposição mental que a gerou, a certeza de todas as assim chamadas leis da física e da química torna-se, agora, vulnerável. 
Aqui, uma objeção perfeitamente desculpável pode ser antecipada e respondida. "Eu garanto", o cientista dirá - de fato, deve dizer - "que qualquer pressuposição em favor de átomos perfeitamente similares desaparece sob análise; garanto que nossa suspeita inicial sobre tais tipos de átomos aparece a partir de uma imperfeição mental; ainda assim, mantenho minhas teorias intactas com a verificação experimental". Dessa forma, o turbilhão do tempo traz consigo suas vinganças. Aqui está a ciência tomando a armadura deixada pela religião e apoiando suas afirmações na profecia! O cientista prediz um planeta, um elemento, uma fórmula e a coisa ou vem mais ou menos como ele a previu ou ele faz uma descoberta. Agora, o fato único das médias explica todo o problema.

É fato bem sabido que em qualquer teatro, durante o curso de uma peça bem-sucedida, quase o mesmo número de pessoas virá na segunda-feira, ou na terça, ou em qualquer outro dia, e que essas pessoas irão se distribuir quase da mesma forma pelo auditório. Assim, muitos irão para o fosso, muitos para perto dos camarins, outros para os camarotes. Portanto, muito papel será necessário para arredondar os totais. O gerente é capaz de dar todos esses números de antemão, com valores muito próximos da verdade. Ainda assim, nenhum desses espectadores é o mesmo que outro; cada um tem seus cuidados e dores individuais, desejos e motivos, e chega e sai de acordo com as necessidades de sua vida única. Aqui e ali existem interrupções na monótona seqüência de sessões; um louco, talvez, venha ao teatro, atire com uma pistola e esvazie a galeria. Mas tome um teatro suficientemente grande e um número de vezes suficientemente grande e se torna possível definir o resultado de uma sessão média a partir da soma das ações de várias pessoas similares supostamente indistinguíveis. O mesmo para os átomos: é possível pensá-los como coisas únicas, cada uma com suas idiossincrasias e, ainda assim, considerar a chamada verificação da teoria atômica com tranqüilidade. encaixá-los em uma linguagem manuseável. Mas isso não leva Wells a desacreditar da ciência: leva-o apenas a colocá-la dentro de limites definidos. Sem que a própria reconheça suas limitações, torna-se religião. Ao mesmo tempo, tal reconhecimento não deve ser entendido como renúncia. A ciência, tal como está estruturada, sofre de uma limitação essencial - que a redescoberta do único põe a nu ,- o que não quer dizer que deva ser descartada.

O interessante do texto é que seu autor é o mais influente escritor de um gênero que só encontraria expressão plena no século xx: a ficção científica. Esta carece de definição precisa mas, grosso modo, pode-se dizer que lida com descobertas - científicas, principalmente - e seus desenvolvimentos imediatos ou futuros. Um de seus subgêneros, portanto, é a literatura futurística, com representantes desde o século XVII, mas só completamente realizada depois da publicação de $A$ máquina do tempo, novela na qual é desenvolvida a idéia de que o progresso científico, contrariamente ao pensamento predominante em fins do século XIX, levaria à degradação da humanidade. Wells é, assim, o homem que forja a idéia que o século XX tem de seu futuro Desde os imensos prédios e máquinas de Metrópolis(filme de Fritz Lang, de 1926), até a opressão urbana de Blade Runner (filme de Ridley Scott, de 1982), tudo tem origem em Wells, em suas histórias futurísticas. 
Mas quando o átomo maluco aparece, o crente no único permanece calmo, enquanto os ouvidos do químico esquentam, seu comportamento torna-se nervoso e suscetível e ele murmura certas coisas pouco razoáveis acerca de erro experimental. Ou possivelmente, como aconteceu depois com um átomo extravagante sobre uma placa sensível, ele imagine que fantasmas curiosos ou ciumentos estão atrapalhando seus experimentos.

Podemos aqui chamar a atenção para a largura pouco razoável da margem de erro experimental que os cientistas permitem. Eles afirmam, por exemplo, como ilustração de sua própria teoria atômica, que, na água, hidrogênio e oxigênio invariavelmente existem numa razão inteira de um para oito. Qualquer químico confiável, se o leitor puder encontrar um e espremê-lo, confessará que as análises mais acuradas e elaboradas da água têm dado resultados fracionários e variados; a razão dos compostos dá errado, teoricamente falando, às vezes à esquerda da decimal. O químico consegue melhores resultados para si mesmo quando toma grandes quantidades e despreza as frações. As discrepâncias, tão comunente notadas pelos novatos entre resultados experimentais e teóricos na física e química práticas, são com freqüência extremamente impressionantes e instrutivas nesse contexto. No início, o estudante é ingenuamente honesto mas, depois, aprende a manipular seus equipamentos - um eufemismo de laboratório.

Deixando os átomos comuns para o químico comum, podemos, em seguida, aludir brevemente às conseqüências da redescoberta para a moralidade. Estamos aqui em um terreno onde, modestamente, quase tememos pisar. Existe a terrível possibilidade de despertar a ira e encontrar as duras denúncias de certos homens de letras, que tomaram a moralidade pública sob sua proteção. Podemos, no entanto, notar que os seres são únicos, as circunstâncias são únicas e que, portanto, não podemos pensar em regular nossa conduta a partir de dicta abrangentes. Um respeito estrito à verdade nos compele a adicionar que os princípios são dicta abrangentes: são substitutos, de valor mais que discutível, para um estudo de casos individuais. Um filantropo apressado poderia vestir um milhar de pobres almas com casacos prontos, todos do mesmo tamanho. Mas, se realmente as quisesse bem vestidas, deveria mandá-las uma a uma para o alfaiate.

Não existe razão por que um homem que tenha até hoje se apegado a, e se sentido honestamente orgulhoso de, altos princípios, deva ficar envergonhado por ter compartilhado um erro comum - desde que esteja preparado para um abandono franco. Mas embora um princípio, assim como um fetiche, possa ainda ser conveniente como um lançador de mísseis, ou divertido como uma curiosidade, seu suposto valor e honorabilidade se desfazem com nossa descoberta. Por fim, podemos nos afastar de provas e conseqüências e notar brevemente como essa grande redescoberta chegou a ser pensada. O período de mais negra ignorância, quando os homens deram as costas à natureza e acreditaram em números místicos, já passou faz tempo. Mesmo os crânios dos acadêmicos já se desfizeram 
em pó por esta época e seus livros estão aos pedaços. O trabalho de Darwin e de Wallace foi a afirmação clara da unicidade das coisas viventes; e os físicos e químicos estão agora engajados no hesitante próximo passo. Devem dá-lo mais cedo ou mais tarde. Estamos na véspera da emancipação final do homem da razoabilidade rígida, do último traço do pensamento rigidamente mecânico dos séculos XVII e XVIII. O químico comum é um Rip Van Winkle desses tempos enterrados. Sua cova o espera na primeira oportunidade, bocejando.

A elegante e querida imagem de um universo de almas feitas de paixões e de princípios colocadas em corpos feitos de átomos, todos colocados juntos de maneira tão perfeita e acabada na Criação, se esvanece numa série de visões dissolvidas a que chamamos marcha do pensamento humano. Não mais acreditamos, não importa o credo a que estejamos afeitos, numa deidade cujos desígnios sejam tão idiotas e pequenos que até um bispo seja capaz de traçá-los e detectar uma alma irmã. Mesmo alguns dos mais pios não podem deixar de rir do mundo de Milton - equilibrado perfeitamente no centro de esferas cristalinas que se sustentam através de uma cadeia dourada presa nas ameias celestes. Não mais especulamos "Que variados seres habitam as estrelas" [a partir de Alexander Pope], porque não temos razão alguma para esperar vida noutro lugar além deste planeta. Estamos um século à frente daquele cosmos de Nuremberg e, em seu lugar, assoma-se a vaga sugestão do inefável do mistério único da vida. Devemos a Goethe, o pai intelectual do século XIX, a figura de um terrível tear, que com fios únicos e inalcançáveis, produz um padrão acima de toda interpretação humana. Número-Ordem parece agora ser a última lei no universo; no tempo de nossos bisavós, era a primeira lei dos céus. humana.

Assim gira a gaiola de esquilo da filosofia

Estudos Avançados 9 (25), 1995
É com ele que nasce a idéia de que o futuro propiciado pelos desenvolvimentos científico e técnológico guarda momentos de pesadelo para todos os que chegarem até lá. Wells é o pai do futuro negro que povoa quase todo o atual imaginário futurístico.

E qual a origem desse pessimismo essencial de Wells? Uma descrença radical da ciência. O conhecimento científico, na verdade, dá muito menos que aquilo que dele se espera. Seus artífices, cheios de si, estão quase nada mais capacitados que o homem comum para compreender a natureza e seus meios. Mas essa nova religião tem tantos adeptos que já se tornou difícil denunciá-la. E, pior, ela é extremamente poderosa em seus dons. Essa é a imagem que Wells entretém da atividade científica, imagem que não tem nada de sensacionalismo gratuito, que é embasada em estudo e reflexão. O resultado dessa linha de pensamento é a ficção pessimista e o resultado dessa ficção é a imagem que todos, hoje, temos do futuro.

Assim, mais que simplesmente uma provocação escrita por um jovem de 25 anos, $A$ redescoberta do unnico apresenta a base sobre a qual assentam os limites da imaginação futurística do século XX.

* Doutor em Sociologia pela USP e pesquisador -bolsista do CNPQ. 
A ciência é um fósforo que só recentemente o homem acendeu. Ele pensava estar em uma sala - em momentos de devoção, em um templo - e que sua luz se refletiria nas paredes e as mostraria inscritas com maravilhosos segredos e pilares entalhados com sistemas filosóficos colocados em harmonia. É uma sensação curiosa, agora que o primeiro clarão se foi e a chama queima mais clara, ver suas mãos brilharem, ele mesmo e o ponto em que se encontra apenas visíveis e, à sua volta, em lugar de todo aquele conforto humano e beleza que antecipara trevas ainda.

Nota

l Cavalo de frisa. Peça de defesa, de uso militar. Em francês no original.

Tradução de Jesus de Paula Assis. O original em inglês - The Rediscovery of the Unique encontra-se à disposição do leitor no IEA-USP para eventual consulta. 


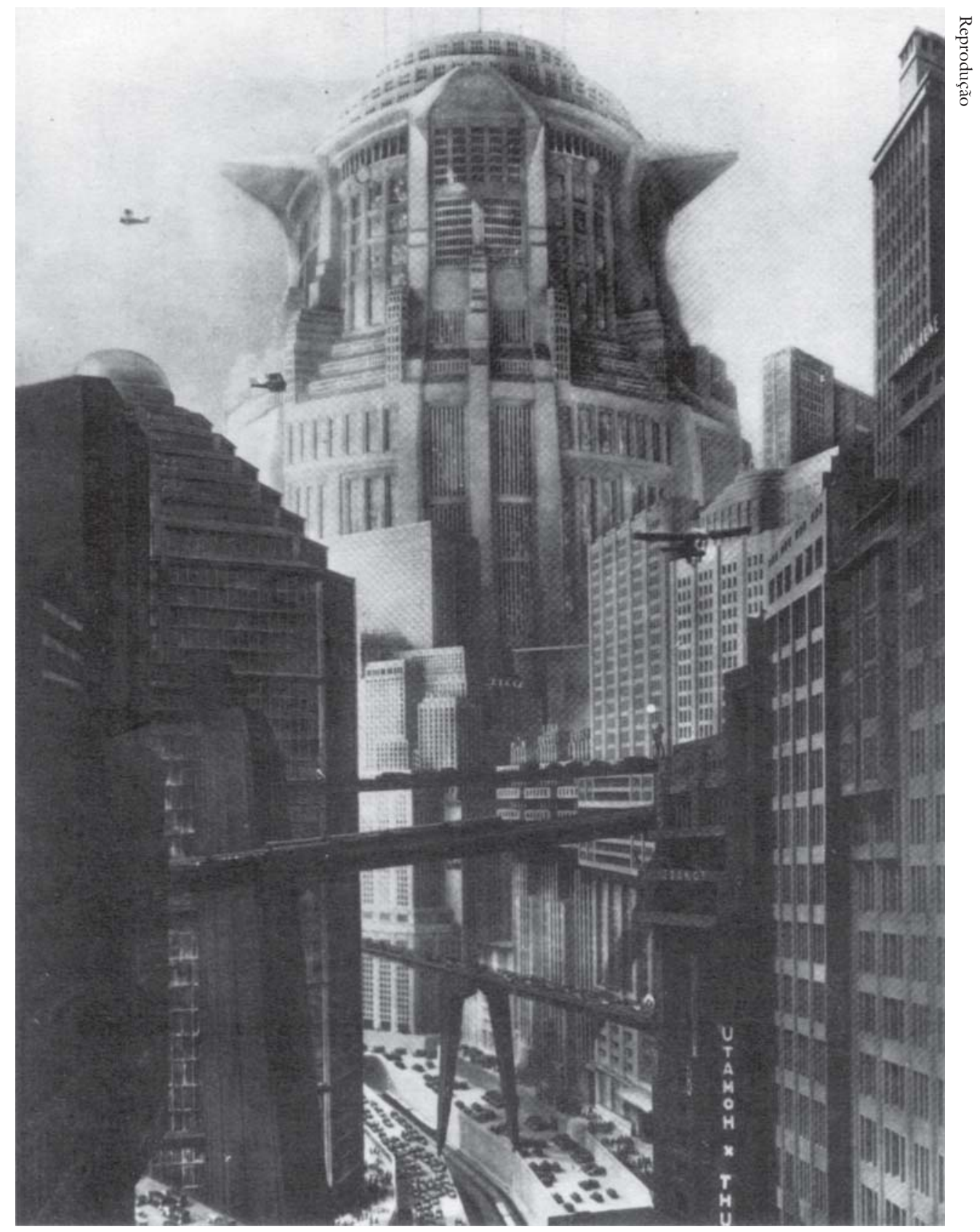

Cena do filme Metrópolis, (1926), de Fritz Lang's 